\title{
Localization of Chitin Synthase Activity in Subcellular Fractions of Schizophyllum commune Protoplasts
}

\author{
By C. A. VERMEULEN, M. B. J. M. RAEVEN AND J. G. H. WESSELS \\ Department of Developmental Plant Biology, Biological Centre, \\ University of Groningen, Haren, The Netherlands
}

(Received 31 October 1978)

\begin{abstract}
Plasma membranes of Schizophyllum commune were stabilized against fragmentation by coating protoplasts with concanavalin A (Con A). A uniform distribution of Con A over the membrane was demonstrated cytochemically. After lysis of the protoplasts in the presence of an inhibitor of proteolysis, plasma membranes were purified and, together with other subcellular fractions, assayed for chitin synthase activity. About $50 \%$ of the chitin synthase activity was associated with the plasma membranes and largely occurred in an active form. About $30 \%$ of the chitin synthase, in an inactive form, was recovered in fractions sedimenting at 40000 to $300000 \mathrm{~g}$. The product of the plasma membrane-bound enzyme was shown to be $\alpha$-chitin occurring as microfibrils (about $6 \mathrm{~nm}$ wide). The chitin synthase could not be detached from the plasma membranes by incubation with substrate and activator at $0{ }^{\circ} \mathrm{C}$ and gradient centrifugation showed that the synthesized chitin remained associated with the plasma membranes.
\end{abstract}

\section{INTRODUCTION}

Chitin synthase (uridine-5'-diphosphate-2-acetamido-2-deoxy-D-glucose:chitin-4- $\beta$-acetamidodeoxyglucosyltransferase; EC 2.4.1.16), first described in Neurospora crassa by Glaser \& Brown (1957), has since been detected in all groups of chitin-containing fungi. Localization of the enzyme and the site of synthesis of chitin, however, is still controversial. In the Mucorales most of the chitin synthase activity is associated with a heavy centrifugal fraction containing cell walls (McMurrough et al., 1971; Jan, 1974; Peberdy \& Moore, 1975; van Laere \& Carlier, 1978). This has led to the hypothesis that the enzyme is localized and functional in the wall (Bartnicki-Garcia, 1973). However, Jan (1974) proposed the plasma membrane as the principal site; the high activity in the wall fraction would then be due to contamination of the walls with plasma membranes. In contrast, in ascomycetes (Ryder \& Peberdy, 1977; Lopez-Romero \& Ruiz-Herrera, 1976) and basidiomycetes (Gooday, 1977) most of the chitin synthase activity is recovered from a microsomal fraction. Substantial evidence for the attachment of chitin synthase to the plasma membrane has been reported by Durán et al. (1975) for Saccharomyces cerevisiae and recently by Braun \& Calderone (1978) for Candida albicans. In addition, Durán et al. (1975) found that most of the enzyme was present in a zymogen state which could be activated by limited proteolytic digestion. Activation of chitin synthase by proteolytic enzymes has since been found in many other fungi (Ruiz-Herrera \& Bartnicki-Garcia, 1976; van Laere \& Carlier, 1978; Lopez-Romero \& Ruiz-Herrera, 1976; Archer, 1977; Ryder \& Peberdy, 1977). The recognition that the enzyme can occur in a zymogen form also led to the isolation of zymogen particles from the $54000 \mathrm{~g}$ supernatants of cell-free extracts of the yeast form of Mucor rouxii (Ruiz-Herrera et al., 1975; Bracker et al., 1976). Such particles, called chitosomes, were also found when chitin synthase was solubilized from crude membrane preparations 
by incubating these preparations with the substrate uridine- 5 -diphospho- $N$-acetyl-Dglucosamine (UDP-GlcNAc) and the activator $N$-acetylglucosamine (GlcNAc) at $0{ }^{\circ} \mathrm{C}$ (Ruiz-Herrera \& Bartnicki-Garcia, 1974; Ruiz-Herrera et al., 1975).

Electron microscopy and high-resolution autoradiography of regenerating protoplasts of Schizophyllum commune (van der Valk \& Wessels, 1976, 1977) have shown that chitin is only synthesized in close association with the plasma membrane. The present study was undertaken to obtain more information about the localization and activity of chitin synthase in subcellular fractions of these protoplasts.

\section{METHODS}

Growth of mycelium and preparation of protoplasts. Dikaryotic fruiting mycelium of Schizophyllum commune, obtained by mating strains $1-40(A 4 I B 4 I)$ and 1-50 (A5I B5I), was grown on minimal agar medium (Wessels, 1965) at $24^{\circ} \mathrm{C}$ in Petri dishes placed upside down. Basidiospores accumulating on the lids were collected regularly and stored at $-40^{\circ} \mathrm{C}$ in sterile water. Mycelium was grown from basidiospores inoculated at a concentration of approximately $5 \times 10^{8} \mathrm{ml}^{-1}$ in liquid minimal medium and incubated for $20 \mathrm{~h}$ at $24{ }^{\circ} \mathrm{C}$ on a gyratory shaker (New Brunswick Scientific Co.) at $250 \mathrm{rev} . \mathrm{min}^{-1}$. The mycelium was harvested by centrifugation $\left(2000 \mathrm{~g}, 20 \mathrm{~min}\right.$ ) and washed once with $0.5 \mathrm{M}-\mathrm{MgSO}_{4}$. Protoplasts were prepared according to the procedure of de Vries \& Wessels (1975), except that the incubation with wall lytic enzymes and the washings of protoplasts were carried out in $0.5 \mathrm{M}-\mathrm{MgSO}_{4}$ without added sodium maleate. Streptomycin sulphate ( $\left.50 \mu \mathrm{g} \mathrm{ml}^{-1}\right)$ and penicillin potassium $\left(50 \mu \mathrm{g} \mathrm{ml}^{-1} ; 1585 \mathrm{U} \mathrm{mg}^{-1}\right)$ were added to the lytic enzymes to prevent bacterial growth.

Coating of protoplasts with concanavalin $A($ Con $A)$. Protoplast suspensions in $0.5 \mathrm{M}-\mathrm{MgSO}_{4}$ were diluted fivefold with HEPES ( $N$-2-hydroxyethylpiperazine- $N^{\prime}$-2-ethanesulphonic acid)/mannitol buffer $(0.05 \mathrm{M}$ HEPES, $0.5 \mathrm{M}$-mannitol, $5 \mathrm{mM}-\mathrm{MgCl}_{2} ; \mathrm{pH} \mathrm{6.8)}$ and centrifuged for $5 \mathrm{~min}$ at $350 \mathrm{~g}$. The sedimented protoplasts were carefully resuspended in 1 to $3 \mathrm{ml}$ HEPES/mannitol buffer, mixed with 1 vol. HEPES/mannitol buffer containing $0.5 \mathrm{mg}$ Con A ml-1 with or without $5 \mu \mathrm{Ci}\left[{ }^{3} \mathrm{H}\right] \mathrm{Con} \mathrm{A}$ and incubated for $10 \mathrm{~min}$ at $24^{\circ} \mathrm{C}$. The protoplasts were then collected by centrifugation $(5 \mathrm{~min}, 350 \mathrm{~g})$ and washed twice with HEPES/ mannitol buffer.

Preparation of plasma membranes and other subcellular fractions. Protoplasts were lysed by suspending the pelleted protoplasts in $4 \mathrm{ml} 0.01 \mathrm{M}$-Tris/ $\mathrm{HCl}$ containing $2 \mathrm{~mm}$-EDTA, $\mathrm{pH} \mathrm{7.5}$, to which was added $20 \mu 1$ of a $120 \mathrm{~mm}$ solution of the protease inhibitor phenylmethylsulphonyl fluoride (PMSF) in $96 \%(\mathrm{v} / \mathrm{v})$ ethanol (Durán et al., 1975), and passing the suspension twice through a syringe with a needle of $0.65 \mathrm{~mm}$ internal diameter. Part of the lysate was directly centrifuged for $1 \mathrm{~h}$ at $300000 \mathrm{~g}$. The remaining part was layered on 2 vol. $0.1 \mathrm{M}$-Tris/ $\mathrm{HCl}$ containing $0.5 \mathrm{M}$-mannitol, $2 \mathrm{mM}$-EDTA and $0.6 \mathrm{mM}-\mathrm{PMSF}, \mathrm{pH} 7.5$, and centrifuged for $20 \mathrm{~min}$ at $650 \mathrm{~g}$. The pellet contained the majority of plasma membranes; the supernatant was differentially centrifuged at $10000,40000,100000$ and $300000 \mathrm{~g}$ for $1 \mathrm{~h}$ each. All pellets were resuspended in $0.02 \mathrm{M}$-Tris/ $\mathrm{HCl}$ containing $10 \mathrm{mM}-\mathrm{MgCl}_{2}, \mathrm{pH} \mathrm{7.5}$, kept on ice till the end of the last run, and simultaneously assayed for chitin synthase.

Chitin synthase assay. Proteolytic activation of chitin synthase was done by adding $0.5 \mu \mathrm{g}$ trypsin in $10 \mu \mathrm{l}$ $0.02 \mathrm{M}-\mathrm{Tris} / \mathrm{HCl}$ containing $10 \mathrm{mM}-\mathrm{MgCl}_{2}, \mathrm{pH} 7.5$ (incubation buffer) to $200 \mu \mathrm{l}$ of an enzyme suspension. This amount of trypsin proved to be optimal for activation. After $10 \mathrm{~min}$ at $24^{\circ} \mathrm{C}$, the reaction was terminated by adding $1 \mu \mathrm{g}$ soybean trypsin inhibitor in $10 \mu \mathrm{l}$ incubation buffer. To samples not to be activated, $20 \mu \mathrm{l}$ incubation buffer was added. The chitin synthase reaction was started by adding $100 \mu \mathrm{l}$ of a solution

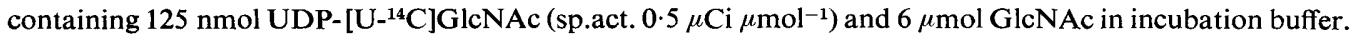
After $1 \mathrm{~h}$ incubation at $24^{\circ} \mathrm{C}$, the reaction was stopped by adding $100 \mu 150 \%(\mathrm{w} / \mathrm{v})$ trichloroacetic acid (TCA). The precipitate was collected on Whatman GF/A glass fibre discs, washed with $30 \mathrm{ml} 5 \%$ TCA in $20 \mathrm{~mm}-\mathrm{Na}_{4} \mathrm{P}_{2} \mathrm{O}_{7} \cdot 10 \mathrm{H}_{2} \mathrm{O}$ and finally with $5 \mathrm{ml} 96 \%$ ethanol. The filters were dried at $70{ }^{\circ} \mathrm{C}$ and the radioactivity was determined.

Protein was determined in TCA-precipitated samples by Lowry's method, using bovine serum albumin as a standard.

Characterization of the reaction product. The synthesized product was extracted with $1 \mathrm{M}-\mathrm{NaOH}(20 \mathrm{~min}$ at $60{ }^{\circ} \mathrm{C}$ ). The alkaline extract was neutralized and alkali-soluble material was collected by precipitation with 2 vol. $96 \%$ ethanol. Both the alkali-soluble and alkali-insoluble fractions were hydrolysed with $6 \mathrm{M}-\mathrm{HCl}$ at $120^{\circ} \mathrm{C}$ for $2 \mathrm{~h}$. After drying by evaporation, the fractions were chromatographed on cellulose thin-layer plates with pyridine/ethyl acetate/acetic acid/water (36:36:7:21, by vol.) as solvent.

Spots were detected by scanning for radioactivity (Berthold Dünnschicht scanner II). Enzymic degradation was performed with chitinase $\left(1 \mathrm{mg} \mathrm{ml}^{-1}\right)$ and $\beta$-glucosidase $\left(1 \mathrm{mg} \mathrm{ml}^{-1}\right)$ in $2 \mathrm{mM}$-sodium acetate (pH 5.8) 
at $30^{\circ} \mathrm{C}$ for $18 \mathrm{~h}$. The solubilized material was freeze-dried and chromatographed as described above. The $\mathrm{X}$-ray pattern of the alkali-insoluble product was obtained by Ni-filtered $\mathrm{Cu}-K_{\alpha}$ irradiation through a pinhole collimator $40 \mathrm{~mm}$ long and $0.5 \mathrm{~mm}$ wide.

Density gradient centrifugation. Samples $(1 \mathrm{ml})$ were layered on $14.0 \mathrm{ml}$ of a linear 15 to $65 \%(\mathrm{v} / \mathrm{v})$ Renografin gradient in $0.01 \mathrm{M}$-Tris $/ \mathrm{HCl}, \mathrm{pH} 7 \cdot 5$, and centrifuged for $27 \mathrm{~h}$ at $66000 \mathrm{~g}$ at $4{ }^{\circ} \mathrm{C}$ in a Beckman$\mathrm{L} 2$ ultracentrifuge equipped with an SW27 rotor. Fractions $(0.6 \mathrm{ml})$ were removed from the bottom, precipitated with $10 \%$ TCA, washed and dried as described above and assayed for radioactivity.

Determination of radioactivity. Filters with ${ }^{14} \mathrm{C}$-labelled material were placed in scintillation vials containing $8 \mathrm{ml}$ toluene and $0.4 \%$ (w/v) diphenyloxazole (PPO). Bound $\left[{ }^{3} \mathrm{H}\right] \mathrm{Con} \mathrm{A}$ was determined by first dissolving the material in $0.4 \mathrm{ml}$ Soluene-100 (Packard) for $15 \mathrm{~min}$ at $60{ }^{\circ} \mathrm{C}$ before adding the toluene/PPO mixture. Radioactive samples from the density gradient centrifugation containing both ${ }^{3} \mathrm{H}$ and ${ }^{14} \mathrm{C}$ were burnt in a Tri-Carb sample oxidizer (Packard) and then ${ }^{3} \mathrm{H}$ and ${ }^{14} \mathrm{C}$ were counted separately according to the instructions of the manufacturer. The monophase-containing vials were supplemented with sodium thiosulphate $[0.15 \mathrm{ml}$ of a $50 \%(\mathrm{w} / \mathrm{v})$ solution] to reduce the quenching by iodine which was liberated from Renografin during the burning procedure.

Electron microscopy. Protoplasts, with or without attached Con A, were prefixed for 5 min at $4{ }^{\circ} \mathrm{C}$ with $2.5 \%(\mathrm{w} / \mathrm{v})$ glutaraldehyde in $0.05 \mathrm{M}$-HEPES containing $5 \mathrm{mM}-\mathrm{MgCl}_{2}$ and with $0.05 \mathrm{M}-\mathrm{mannitol}$ added to obtain an osmolality of $0.55(\mathrm{pH} \mathrm{6.8)}$. They were then washed by centrifugation $(5 \mathrm{~min}, 350 \mathrm{~g})$ with $0.05 \mathrm{M}-$ HEPES containing $5 \mathrm{~mm}-\mathrm{MgCl}_{2}$ and $0.45 \mathrm{M}$-mannitol (pH 6.8;0.55 osmolal) and incubated for 30 min at

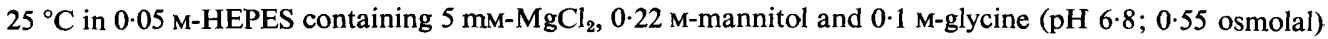
to block free aldehyde groups (Huet \& Garrido, 1972). Protoplasts were then incubated with horseradish peroxidase (HRP; $1 \mathrm{mg} \mathrm{ml}^{-1}$ ) in $0.05 \mathrm{M}-\mathrm{HEPES}$ containing $5 \mathrm{mM}-\mathrm{MgCl}_{2}$ and $0.45 \mathrm{M}$-mannitol (pH 6.8; 0.55 osmolal) at $25^{\circ} \mathrm{C}$ for 20 min to allow attachment of this enzyme to membrane-bound Con A (Bernhard \& Avrameas, 1971). After washing, a modified diaminobenzidine (DAB) reaction (Graham \& Karnovsky, 1966) was carried out in $0.05 \mathrm{M}-\mathrm{Tris} / \mathrm{HCl}(\mathrm{pH} 7.5)$ containing $0.5 \mathrm{mg} \mathrm{DAB} \mathrm{ml}{ }^{-1}, 0.03 \% \mathrm{H}_{2} \mathrm{O}_{2}, 5 \mathrm{mM}_{-} \mathrm{MgCl}_{2}$ and $0.45 \mathrm{M}$-mannitol for $15 \mathrm{~min}$ at $25^{\circ} \mathrm{C}$. Protoplasts were then washed in $0.05 \mathrm{M}$-HEPES containing $5 \mathrm{~mm}-$ $\mathrm{MgCl}_{2}$ and $0.45 \mathrm{M}$-mannitol (pH 6.8; 0.55 osmolal), fixed with $2.5 \%$ glutaraldehyde in $0.05 \mathrm{M}$-HEPES containing $5 \mathrm{mM}-\mathrm{MgCl}_{2}$ and $0.05 \mathrm{M}-$ mannitol ( $\mathrm{pH} 6.8 ; 0.55$ osmolal), dehydrated in a graded series of ethanol and embedded in Epon 812. Thin sections were examined without post-staining in a Philips EM300 electron microscope. $\mathrm{OsO}_{4}$ fixation as used in the original procedure was omitted because the black precipitate formed from DAB by HRP produced enough contrast to be visualized in the electron microscope.

For the cytochemical identification of Con A-coated membranes in subcellular fractions, Con A-coated protoplasts were directly incubated with HRP for $5 \mathrm{~min}$ as described above without prefixation. Plasma membranes were collected $(650 \mathrm{~g})$ and other membranes were sedimented from the supernatant by centrifugation at $104000 \mathrm{~g}$ for $1 \mathrm{~h}$. Both membrane fractions were washed with $0.05 \mathrm{M}-\mathrm{Tris} / \mathrm{HCl}(\mathrm{pH} 7 \cdot 5)$ containing $5 \mathrm{~mm}-\mathrm{MgCl}_{2}$ by centrifuging for $1 \mathrm{~h}$ at $104000 \mathrm{~g}$, and then incubated for $5 \mathrm{~min}$ with DAB as described above. Pellets were fixed with $2.5 \%$ glutaraldehyde in $0.1 \mathrm{M}$-sodium cacodylate containing $5 \mathrm{mM}-\mathrm{MgCl}_{2}$, pH 7.4, dehydrated and embedded as described above.

For visualizing the product of chitin synthase activity, incubated samples were first extracted with $1 \mathrm{M}$ $\mathrm{NaOH}\left(20 \mathrm{~min}\right.$ at $\left.60^{\circ} \mathrm{C}\right)$, and then the insoluble fractions were washed with water and suspensions were placed on collodion-coated grids. They were either shadowed with platinum at an angle of $15^{\circ}$ or negatively siained with $0.5 \%(\mathrm{w} / \mathrm{v})$ aqueous uranyl acetate.

Chemicals. Trypsin, $\beta$-glucosidase, PMSF, HRP, UDP-GlcNAc, GlcNAc and streptomycin sulphate were purchased from Sigma; pronase from Calbiochem; DAB.4HCl from Serva (Heidelberg, West Germany); soybean trypsin inhibitor from Boehringer; Con A, chitinase (Streptococcus griseus) and penicillin potassium from ICN Pharmaceuticals (Cleveland, Ohio, U.S.A.); Renografin from Schering (Berlin, West Germany); and crustacean chitin from Fluka (Buchs, Switzerland). The radiochemicals UDP-[U- $\left.{ }^{14} \mathrm{C}\right] \mathrm{GlcNAc}$ (sp.act. $200 \mathrm{mCi} \mathrm{mmol}^{-1}$ ) and $\left[N\right.$-acetyl $\left.{ }^{3} \mathrm{H}\right] \mathrm{Con} \mathrm{A}$ (sp.act. $22 \cdot 5 \mathrm{Ci} \mathrm{mmol}^{-1}$ ) were obtained from The Radiochemical Centre (Amersham). Polyoxin D was a gift from the Kaken Co. (Tokyo, Japan).

\section{RESULTS}

\section{Visualization of Con A binding by electron microscopy}

The identification of plasma membranes among subcellular fractions of lysed Con Acoated protoplasts on the basis of the amount of Con A present in these fractions is only valid if the Con $A$ is uniformly bound to the plasma membrane surface. To verify this, Con A-treated protoplasts were incubated with HRP and the Con A-HRP complex was visualized cytochemically. A uniform distribution of HRP activity on the protoplast surface 

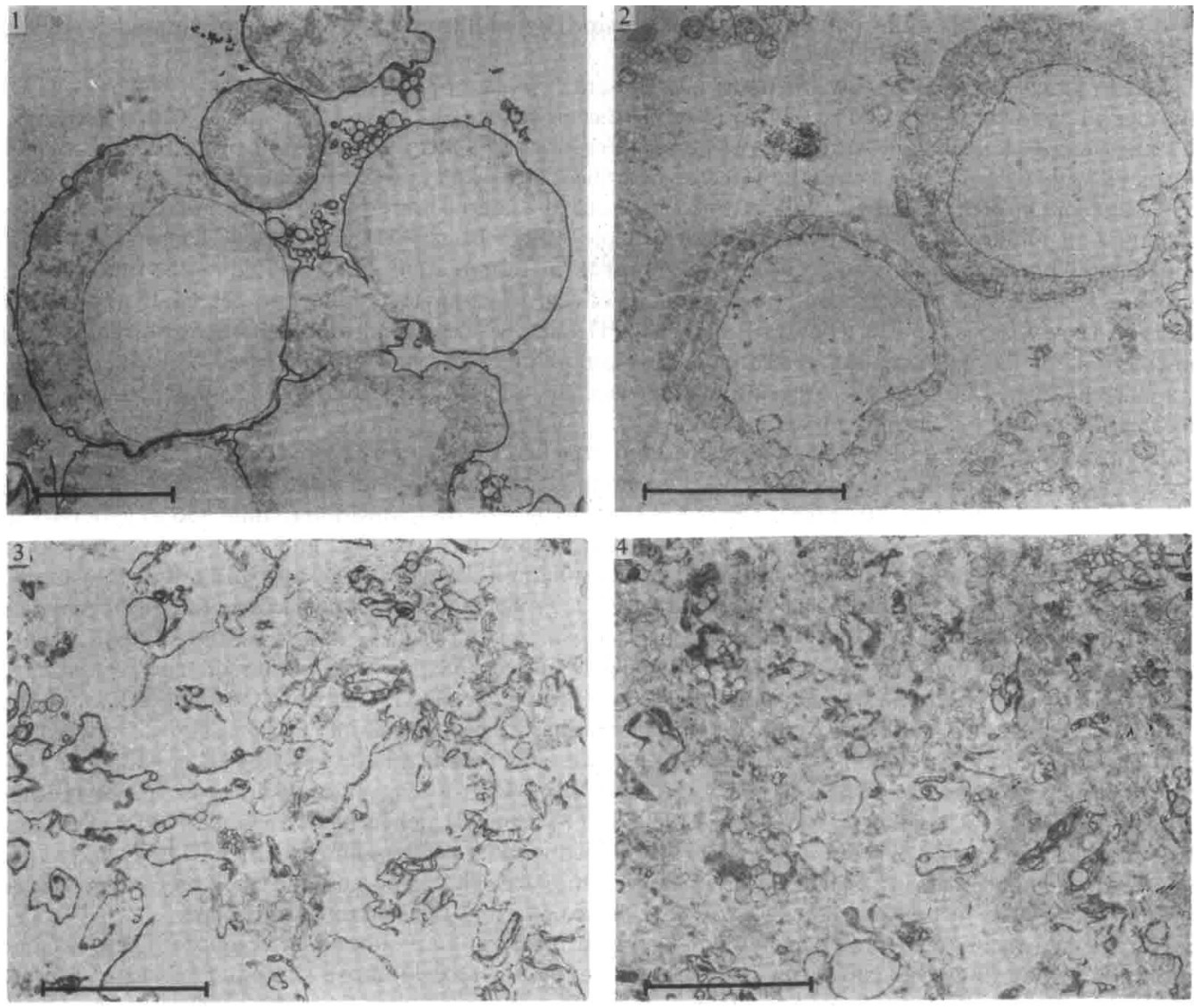

All bar markers represent $5 \mu \mathrm{m}$.

Fig. 1. Protoplasts of Schizophyllum commune coated with concanavalin A (Con A) which was then labelled with horseradish peroxidase (HRP) and visualized by staining with diaminobenzidine (DAB). The protoplast surface is uniformly stained.

Fig. 2. As Fig. 1, except that the protoplasts were not coated with Con A. Note the absence of a DAB-positive surface staining.

Fig. 3. Plasma membrane fraction $(650 \mathrm{~g}$ pellet) of lysed protoplasts coated with Con $\mathrm{A}$ and labelled with HRP prior to lysis. DAB staining was carried out after fractionation. The majority of the membranes are positively stained by the DAB reaction.

Fig. 4. Membranes of lysed protoplasts obtained after sedimenting plasma membranes. The $650 \mathrm{~g}$ supernatant of lysed protoplasts was centrifuged at $104000 \mathrm{~g}$ for $1 \mathrm{~h}$ and stained with DAB. Note the smaller dimensions of these membranes compared with the DAB-positive plasma membranes (Fig. 3).

was demonstrated, except for those regions where free Con A receptor sites were involved in agglutination of protoplasts (Fig. 1). Protoplasts not coated with Con A but treated with HRP did not show HRP activity on their surfaces (Fig. 2), indicating the specificity of the reaction for Con $\mathrm{A}$ bound to the plasma membrane.

Osmotic lysis of protoplasts not coated with Con A produced vesiculated membrane fragments of different sizes which were difficult to separate and to identify on gradients in the centrifuge. Upon lysis of Con A-coated protoplasts, the plasma membranes appeared as practically empty ghosts as observed by phase contrast microscopy. After centrifuging through $0.5 \mathrm{M}$-mannitol at $650 \mathrm{~g}$, the majority of membrane sheets and empty ghosts appeared in the pellet whereas small particles and some membrane fragments were present 
Table 1. Distribution of Con $A$ and chitin synthase activities in subcellular fractions from Con A-treated protoplasts

Protoplasts of Schizophyllum commune were coated with ${ }^{3} \mathrm{H}$-labelled Con A, osmotically lysed and fractionated by centrifugation as detailed in Methods. The amounts of Con $\mathrm{A}$ and the chitin synthase activities with and without proteolytic activation were measured in the crude particles and the various sedimentable fractions.

\begin{tabular}{|c|c|c|c|c|c|}
\hline \multirow[b]{2}{*}{ Fraction } & \multirow[b]{2}{*}{ Protein* } & \multirow[b]{2}{*}{ Con $\mathrm{A}^{*}$} & \multicolumn{2}{|c|}{ Chitin synthase activity $\dagger$} & \multirow[b]{2}{*}{$\begin{array}{l}\text { Activation } \\
\text { factor }\end{array}$} \\
\hline & & & $\begin{array}{l}\text { Without } \\
\text { activation }\end{array}$ & $\begin{array}{c}\text { With } \\
\text { activation }\end{array}$ & \\
\hline $\begin{array}{l}\text { Crude particles } \\
(300000 \mathrm{~g}, 1 \mathrm{~h})\end{array}$ & 100 & 100 & 33.93 & 100 & $2 \cdot 9$ \\
\hline $\begin{array}{l}650 \mathrm{~g}, 20 \mathrm{~min} \\
10000 \mathrm{~g}, 1 \mathrm{~h} \\
40000 \mathrm{~g}, 1 \mathrm{~h} \\
100000 \mathrm{~g}, 1 \mathrm{~h} \\
300000 \mathrm{~g}, 1 \mathrm{~h}\end{array}$ & $\begin{array}{r}48 \cdot 4 \\
30 \cdot 4 \\
1 \cdot 0 \\
1 \cdot 5 \\
10 \cdot 7\end{array}$ & $\begin{array}{r}87 \cdot 0 \\
9 \cdot 6 \\
0 \cdot 3 \\
0 \cdot 2 \\
0 \cdot 2\end{array}$ & $\begin{array}{r}27 \cdot 13 \\
6 \cdot 13 \\
0 \cdot 23 \\
0 \cdot 27 \\
0.36\end{array}$ & $\begin{array}{r}45 \cdot 60 \\
20 \cdot 82 \\
8 \cdot 56 \\
11 \cdot 20 \\
12 \cdot 83\end{array}$ & $\begin{array}{r}1 \cdot 7 \\
3 \cdot 4 \\
37 \cdot 2 \\
41 \cdot 5 \\
35 \cdot 6\end{array}$ \\
\hline Recovery (\%) & $92 \cdot 0$ & $97 \cdot 3$ & $100 \cdot 55$ & $99 \cdot 01$ & $(2 \cdot 9)$ \\
\hline
\end{tabular}

* The amounts of protein (Con A subtracted) and of Con A are expressed as percentages of the total amount of protein and Con $\left.A[145.6 \mu \mathrm{g} \text { (mg protein })^{-1}\right]$ found in the crude particles.

$\dagger$ Chitin synthase activities are expressed as percentages of the activity of the trypsin-treated chitin synthase in the crude particles [197.7 nmol GlcNAc incorporated (mg protein) $\left.{ }^{-1} \mathrm{~h}^{-1}\right]$.

in the supernatant. Electron microscopy of subcellular fractions revealed that the $650 \mathrm{~g}$ pellet consisted almost exclusively of large HRP-positive membranes (Fig. 3). The supernatant contained mainly small HRP-negative membrane fragments and small vesicles and, to some extent, HRP-positive membrane fragments (Fig. 4). On the basis of phase contrast microscopy and the electron microscopical results, it is evident that the $650 \mathrm{~g}$ pellet consisted of fairly well purified plasma membranes. In addition, the results indicated that the amount of Con A present could be used to monitor the presence of plasma membranes in the subcellular fractions.

\section{Distribution of Con $A$ and chitin synthase in subcellular fractions}

Table 1 shows the distribution of $\left[{ }^{3} \mathrm{H}\right]$ Con A and chitin synthase activity after fractionation of lysed protoplasts. The sum of the amounts of Con A and the sum of activities of chitin synthase in the pellets were close to $100 \%$ of the values found for the non-fractionated crude particles. No Con A or chitin synthase activity was found in the post-300000 $\mathrm{g}$ supernatant. The distribution of $\left[{ }^{3} \mathrm{H}\right]$ Con A among the fractions indicates that almost $90 \%$ of the plasma membranes sedimented at $650 \mathrm{~g}$, the rest being in the pellet obtained at $10000 \mathrm{~g}$. Higher speed fractions were virtually free of plasma membranes. About $45 \%$ of the chitin synthase (as measured after activation) was associated with the $650 \mathrm{~g}$ pellet. If it is assumed that all chitin synthase activity in the $650 \mathrm{~g}$ pellet is associated with plasma membranes, it can be calculated from the $\left[{ }^{3} \mathrm{H}\right]$ Con A distribution that the $10000 \mathrm{~g}$ pellet contained another $5 \%$ of the plasma membrane-bound chitin synthase. Thus, $50 \%$ of the chitin synthase of the protoplasts appeared to be bound to plasma membranes. However, if only the chitin synthase that is active without trypsin treatment is taken into account, it appears that about $90 \%$ of the active chitin synthase was associated with the plasma membranes. Whereas the trypsin treatment increased the activity of chitin synthase in the plasma membranes by only a factor of $1 \cdot 7$, the enzyme in the 40000 to $300000 \mathrm{~g}$ fractions appeared to be mainly in an inactive form with an activation factor of 30 to 40 .

\section{Identification of products of plasma membrane-associated chitin synthase}

Approximately $60 \%$ of the product of plasma membrane-associated chitin synthase activity was insoluble in $1 \mathrm{M}-\mathrm{NaOH}$ and in $0: 55 \mathrm{M}-\mathrm{HCl}$. X-ray diffraction powder diagrams 


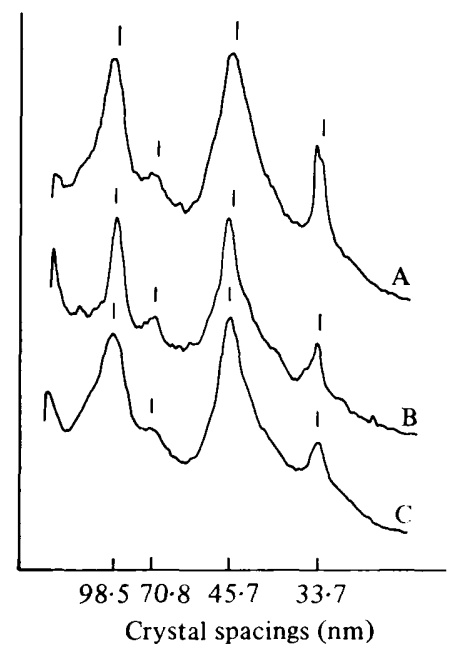

Fig. 5. Radial density tracings of X-ray powder diagrams of chitin. A: Chitin isolated from mycelial walls of Schizophyllum commune according to Sietsma \& Wessels (1977). B: Alkaline-insoluble product of plasma membrane-associated chitin synthase. C: Crustacean chitin purified according to the procedure of Skujins et al. (1965).
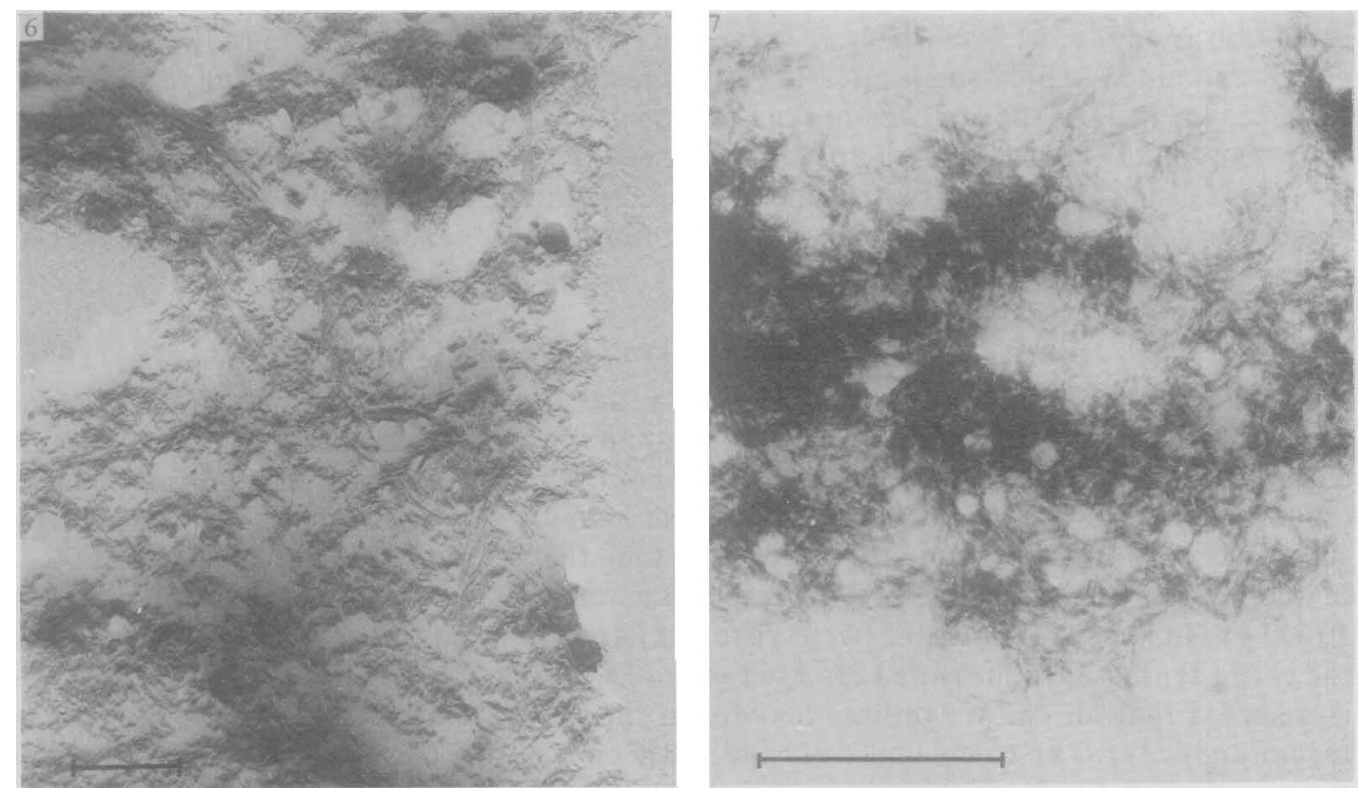

Bar markers represent $0 \cdot 3 \mu \mathrm{m}$.

Fig. 6. Shadowed preparation (platinum $15^{\circ}$ ) of the alkali-insoluble product of plasma membranebound chitin synthase.

Fig. 7. Negatively stained preparation ( $0.5 \%$ aqueous uranyl acetate) of the alkali-insoluble product of plasma membrane-bound chitin synthase.

of the alkali-resistant product of the reaction showed a diffraction pattern characteristic of highly crystalline $\alpha$-chitin, similar to those of crustacean chitin and chitin isolated from hyphal walls of Schizophyllum commune (Fig. 5). Analysis by chromatography of the native product and the alkali-soluble and alkali-insoluble fractions after hydrolysis with $6 \mathrm{M}-\mathrm{HCl}$ revealed the presence of one mobile peak corresponding to glucosamine. After incubation 


\section{Table 2. Effect of substrate and activator on the association between plasma membranes and chitin synthase}

Freshly isolated Con A-coated plasma membranes were preincubated at $0{ }^{\circ} \mathrm{C}$ with buffer $(0.02 \mathrm{M}-$ Tris/ $\mathrm{HCl}, 10 \mathrm{mM}-\mathrm{MgCl}_{2}, \mathrm{pH} \mathrm{7.5)}$ or with buffer containing UDP-GlcNAc (5 mM) and GlcNAc $(20 \mathrm{mM})$. After $1 \mathrm{~h}$ the membranes were centrifuged $\left(40000 \mathrm{~g}, 30 \mathrm{~min}, 4^{\circ} \mathrm{C}\right)$, all samples were brought to $5 \mathrm{~mm}$-UDP-GlcNAc and $20 \mathrm{~mm}$-GlcNAc, and chitin synthase activity was assayed in the sedimented membrane fraction and in the supernatant.

$\begin{array}{ccc}\text { Fraction } & \begin{array}{c}\text { Chitin synthase activity* } \\ \begin{array}{c}\text { Preincubation with } \\ \text { buffer }\end{array}\end{array} & \begin{array}{c}\text { Preincubation with } \\ \text { UDP-GlcNAc and } \\ \text { GlcNAc }\end{array} \\ \text { Plasma membranes } & 100 \cdot 0 & 104.9 \\ \text { Supernatant } & 0.5 & 0.1\end{array}$

* Chitin synthase activities are expressed as percentages of the activity in plasma membranes not preincubated with UDP-GlcNAc and GlcNAc (37.76 $\mathrm{nmol}$ incorporated $\left.\mathbf{h}^{-1}\right)$.

of such fractions with chitinase and $\beta$-glucosidase, 85 to $90 \%$ of the ${ }^{14} \mathrm{C}$ activity became water-soluble. The soluble product of the enzyme reaction corresponded to $N$-acetylglucosamine on the chromatograms.

Electron microscopy of shadowed and negatively stained preparations of the alkaliinsoluble product revealed that the synthesized material consisted of small microfibrils (6 $\mathrm{nm}$ wide) often arranged in thicker bundles forming networks (Figs 6 and 7).

\section{Association of chitin synthesis with plasma membranes}

Plasma membranes were preincubated with UDP-GlcNAc at $0{ }^{\circ} \mathrm{C}$ to determine whether chitin synthase associated with plasma membranes could be solubilized (Ruiz-Herrera \& Bartnicki-Garcia, 1974). The results (Table 2) did not indicate that the enzyme became detached from the membrane. However, this did not exclude the possibility that the enzyme became detached from the membrane at a temperature permitting chitin synthesis. To investigate this possibility, plasma membranes coated with $\left[{ }^{3} \mathrm{H}\right] \mathrm{Con}$ A were incubated with UDP-[U- $\left.{ }^{14} \mathrm{C}\right] \mathrm{GlcNAc}$, to label synthesized chitin with ${ }^{14} \mathrm{C}$, and then centrifuged through a Renografin gradient. The ${ }^{3} \mathrm{H}$ and ${ }^{14} \mathrm{C}$ label banded at exactly the same density (Fig. $8 a$ ), and at about the same density as $\left[{ }^{3} \mathrm{H}\right]$ Con A-coated plasma membranes not incubated with UDP-GlcNAc (not shown). Yet, the chitin synthesized on the membranes could have caused a small shift in the density of the membranes. Therefore, $\left[{ }^{3} \mathrm{H}\right]$ Con A-coated membranes not incubated with UDP-GIcNAc and membranes coated with non-labelled Con A but incubated with UDP-[U-14 C]GlcNAc were mixed in the presence of polyoxin D and centrifuged together on a Renografin gradient. The polyoxin $\mathrm{D}$ was added to prevent any chitin synthesis on the $\left[{ }^{3} \mathrm{H}\right]$ Con A-coated membranes after mixing of the two membrane preparations. Analysis of the ${ }^{3} \mathrm{H}$ and ${ }^{14} \mathrm{C}$ label in the gradient after centrifugation showed a small but definite shift to a higher density of the membranes that were permitted to synthesize chitin (Fig. $8 b$ ). When the membrane-chitin complex was treated with alkali $\left(1 \mathrm{M}-\mathrm{NaOH}\right.$ at $60^{\circ} \mathrm{C}$ for $\left.20 \mathrm{~min}\right)$ and then with chloroform/methanol $\left(2: 1, \mathrm{v} / \mathrm{v}\right.$, at $55^{\circ} \mathrm{C}$ for $30 \mathrm{~min}$ ), the freed chitin sedimented to the bottom of the tube (Fig. $8 \mathrm{c}$ ). Similarly, when less drastic methods were used to disrupt the membranes, such as a treatment with chloroform/methanol alone followed by pronase digestion $\left(1 \mathrm{mg} \mathrm{ml} l^{-1}\right.$ for $18 \mathrm{~h}$ at $\left.37^{\circ} \mathrm{C}\right)$, the chitin also sedimented to the bottom of the tube. 


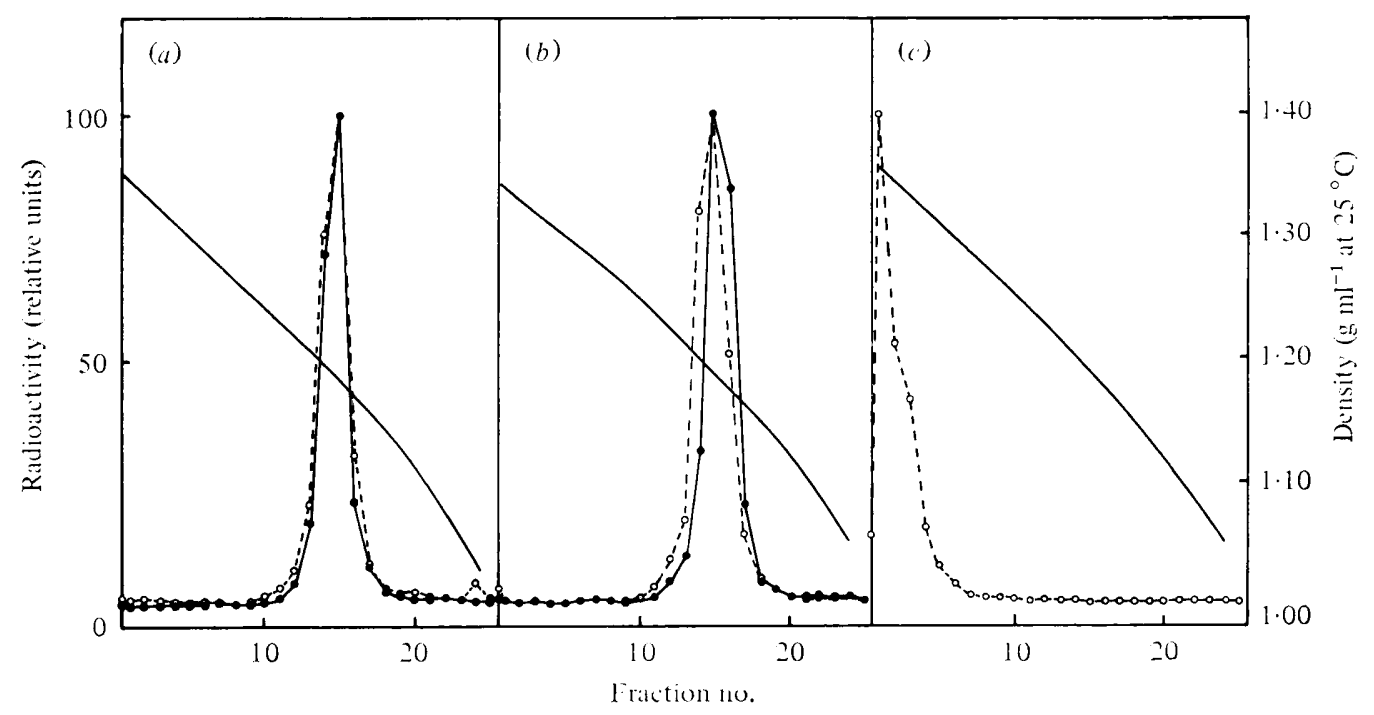

Fig. 8. Renografin gradient centrifugation of Con A-coated plasma membranes (- - ) and synthesized chitin $\left(\mathrm{O}_{---} \mathrm{O}\right)$. Plasma membranes were incubated with UDP-GlcNAc as indicated in Methods, except that the UDP-GlcNAc concentration was $5 \mathrm{~mm}$ and the incubation time was extended to $1.5 \mathrm{~h}$. Density is indicated by the continuous line.

(a) $\left[{ }^{3} \mathrm{H}\right]$ Con A-coated plasma membranes were allowed to synthesize chitin with UDP- $\left[{ }^{14} \mathrm{C}\right]-$ GlcNAc and then centrifuged.

(b) Non-labelled Con A-coated plasma membranes were allowed to synthesize chitin with UDP- $\left[{ }^{14} \mathrm{C}\right]$ GlcNAc. They were then mixed with $\left[{ }^{3} \mathrm{H}\right] \mathrm{Con} \mathrm{A}$-coated plasma membranes in the presence of polyoxin D $\left(50 \mu \mathrm{g} \mathrm{ml}^{-1}\right.$; to prevent any synthesis of chitin on the $\left[{ }^{3} \mathrm{H}\right] \mathrm{Con} A$-coated plasma membranes) and centrifuged.

(c) Non-labelled Con A-coated plasma membranes were allowed to synthesize chitin; the reaction product was treated with $1 \mathrm{M}-\mathrm{NaOH}\left(20 \mathrm{~min}\right.$ at $\left.60^{\circ} \mathrm{C}\right)$ followed by chloroform $/ \mathrm{methanol}(2: 1$, $\mathrm{v} / \mathrm{v}$, at $55^{\circ} \mathrm{C}$ for $30 \mathrm{~min}$ ) and centrifuged.

\section{DISCUSSION}

The lectin Con A stabilizes the plasma membrane of wall-less mutants and protoplasts of fungi (Scarborough, 1975; Durán et al., 1975; Braun \& Calderone, 1978). This phenomenon facilitated the purification of plasma membranes from lysed protoplasts of Schizophyllum commune. However, the use of Con $\mathrm{A}$ as a label for the presence of plasma membrane fragments in subcellular fractions depends on the distribution of Con A receptor sites on the plasma membrane and on the exclusive binding of Con $\mathrm{A}$ to the plasma membrane. The distribution pattern of Con A receptor sites on cell surfaces has been shown to depend on several factors such as cell type, state of differentiation, reaction time with Con A and temperature (Smith \& Revel, 1972; Nicolson, 1974; Graham et al., 1974; Burgess \& Linstead, 1976; Williamson et al., 1976). The results presented in this paper showed that under the conditions used the Con A receptor sites on the protoplasts of Schizophyllum commune visualized by the HRP labelling technique (Bernhard \& Avrameas, 1971) were randomly distributed on the protoplast surface. Con A could not be detected intracellularly. The possibility that this was due to a failure of HRP to label Con A inside the protoplasts seems very remote. Con A has a molecular weight of 110000 (Huet, 1975) and was applied to intact cells, whereas the Con A-labelled cells were prefixed and then exposed to the smaller HRP molecules (mol. wt 44000). A weak DAB-positive reaction was sometimes 
observed in mitochondria and on vacuolar membranes, especially in protoplasts not coated with Con A. This has to be ascribed to a reaction of DAB with cytochromes and other haem proteins (Essner, 1974).

With regard to the cellular location of chitin synthase, the results clearly showed two distinct forms of the enzyme located at different sites. A largely active chitin synthase, representing about $45 \%$ of the total activity, sedimented with plasma membranes. An inactive form of the enzyme, representing about $35 \%$ of the total activity, could be sedimented from post- $10000 \mathrm{~g}$ supernatants of the lysates. The remaining $20 \%$ of the chitin synthase activity sedimented at $10000 \mathrm{~g}$ and occurred in an apparent state of activation intermediate between the enzyme in the plasma membranes and the high-speed fractions. The significance of this fraction is difficult to assess. The presence of Con A indicated that about $10 \%$ of the plasma membranes were in this fraction. However, although the cytochemical localization of Con A on the protoplasts indicated a uniform distribution of Con A over the membranes, the possibility remains that the amount of Con A bound to the membranes varied for different protoplasts. Membranes bearing relatively low amounts of Con A could be present in the $10000 \mathrm{~g}$ pellets. Therefore, it is possible that the fraction of plasma membranes in these pellets was actually higher than calculated on the basis of the Con A present. Alternatively, the $10000 \mathrm{~g}$ pellet represents yet another cellular compartment of chitin synthase. At the moment it is impossible to decide between these alternatives.

The observation that plasma membrane-associated chitin synthase was largely in an active state seems to indicate that the situation in protoplasts from Schizophyllum commune differs from that in Saccharomyces cerevisiae where plasma membrane-bound chitin synthase was found mainly in a zymogen form (Durán et al., 1975). In Saccharomyces cerevisiae protoplasts the presence of a zymogen of chitin synthase in the plasma membrane has been implicated in the synthesis of chitin at the site of septum formation by localized proteolytic activation of the zymogen (Cabib \& Farkas, 1971). In filamentous fungi, chitin is mainly synthesized at the apex of the growing hyphae (Bartnicki-Garcia \& Lippman, 1969; Katz \& Rosenberger, 1971; Gooday, 1971; van der Valk \& Wessels, 1977). Results obtained with chitin synthase preparations from protoplasts derived from apical and subapical regions of hyphae have been interpreted to indicate that apical regions contain chitin synthase in a largely activated state and that in sub-apical regions the enzyme is present as a zymogen (Archer, 1977; Isaac et al., 1978). No evidence for such a preferential location of active enzyme and zymogen along the hyphae was obtained in the present study. The enzymic treatment of germlings of Schizophyllum commune converted virtually the whole mycelium into protoplasts which therefore were derived from both apical and sub-apical regions. Because an inhibitor of proteolysis was included during the isolation of subcellular fractions and because the chitin synthase in the high-speed fractions remained in an inactive form, it is very unlikely that proteolytic activation of plasma membranebound chitin synthase occurred during isolation of the membranes. Yet, the activation factor for the plasma membrane-bound chitin synthase was only $1 \cdot 7$. This makes it unlikely that protoplasts differed in the state of activation of chitin synthase in the plasma membrane reflecting their origin. Because chitin synthesis on freshly isolated protoplasts is not inhibited by cycloheximide (de Vries \& Wessels, 1975), this suggests that during the formation of protoplasts from sub-apical regions chitin synthase was either activated if present in an inactive form in the plasma membrane or newly incorporated into the plasma membrane.

The results of this study further show that in contrast to the plasma membrane-bound enzyme (about $50 \%$ ), the chitin synthase not associated with the plasma membrane largely occurred in an inactive state. The presence of such an inactive enzyme has also been demonstrated in $54000 \mathrm{~g}$ supernatants from cell-free extracts from yeast cells of Mucor rouxii, where it was associated with identifiable particles called chitosomes (Ruiz-Herrera et al., 1975; Bracker et al., 1976). The role of these chitosomes in chitin synthesis has not yet been elucidated but it was suggested that they are extruded through the plasma membrane 
to initiate the synthesis of chitin in the wall. Although the presence of chitosomes in protoplasts of Schizophyllum commune has not been established, it is possible that the inactive form of chitin synthase in the high-speed fractions is represented by such structures. The results do not, however, indicate that chitin synthase is extruded through the plasma membrane, which appeared to be the only site of chitin synthesis. Firstly, it was found that in vivo chitin synthesis occurred in close association with the plasma membrane (van der Valk \& Wessels, 1976, 1977). Secondly, the present study showed that the chitin synthase associated with the plasma membrane was not released during exposure to substrate and activator at low temperature and that chitin produced on isolated plasma membranes remained associated with the membranes. It is possible that the inactive enzyme represents the cytoplasmic transport form of chitin synthase after synthesis of the enzyme. Its inactivity may preclude the synthesis of chitin within the cell before incorporation and activation of the enzyme in the plasma membrane.

This study was supported by the Foundation for Fundamental Biological Research (BION), which is subsidized by the Netherlands Organization for the Advancement of Pure Research (ZWO).

\section{REFERENCES}

ARCHER, D. B. (1977). Chitin biosynthesis in protoplasts and subcellular fractions of Aspergillus fumigatus. Biochemical Journal 164, 653-658.

BARTNICKI-Garcia, S. (1973). Fundamental aspects of hyphal morphogenesis. Symposia of the Society for General Microbiology 23, 245-267.

BARTNICKI-Garcia, S. \& LippMAN, E. (1969). Fungal morphogenesis: cell wall construction in Mucor rouxii. Science 165, 302-304.

Bernhard, W. \& AvRameas, S. (1971). Ultrastructural visualization of cellular carbohydrate components by means of concanavalin A. Experimental Cell Research 64, 232-236.

Bracker, C. E., Ruiz-Herrera, J. \& BartnickiGARCIA, S. (1976). Structure and transformation of chitin synthase particles (chitosomes) during microfibril synthesis in vitro. Proceedings of the National Academy of Sciences of the United States of America 73, 4570-4574.

Braun, P. C. \& Calderone, R. A. (1978). Chitin synthesis in Candida albicans: comparison of yeast and hyphal forms. Journal of Bacteriology 135, 1472-1477.

Burgess, J. \& Linstead, P. J. (1976). Ultrastructural studies of the binding of concanavalin $A$ to the plasmalemma of higher plant protoplasts. Planta 130, 73-79.

CaBib, E. \& Farkas, V. (1971). The control of morphogenesis: an enzymatic mechanism for the initiation of septum formation in yeast. Proceedings of the National Academy of Sciences of the United States of America 68, 2052-2056.

Durán, A., Bowers, B. \& CABIB, E. (1975). Chitin synthetase zymogen is attached to the yeast plasma membrane. Proceedings of the National Academy of Sciences of the United States of America 72, 3952-3955.

ESSNER, E. (1974). Hemoproteins. In Electron Microscopy of Enzymes: Principles and Methods, vol. 2, pp. 1-33. Edited by M. A. Hayat. New York: Van Nostrand Reinhold Co.

Glaser, L. \& Brown, D. H. (1957). The synthesis of chitin in cell-free extracts of Neurospora crassa. Journal of Biological Chemistry 228, 729-742.

GoODAY, G.W. (1971). An autoradiographic study of hyphal growth of some fungi. Journal of General Microbiology 67, 125-133.

GoodAY, G. W. (1977). Biosynthesis of fungal wall mechanisms and implications. Journal of General Microbiology 99, 1-11.

Graham, R. C. \& KarnovsKy, M. J. (1966). The early stages of absorption of injected horseradish peroxidase in the proximal tubules of mouse kidney. Ultrastructural cytochemistry by a new technique. Journal of Histochemistry and Cytochemistry 14, 291-302.

Graham, D. I., Gonatas, N. K. \& Charalampous, F. C. (1974). The undifferentiated and extended forms of C 1300 murine neuroblastoma: an ultrastructural study and detection of concanavalin A binding sites on the plasma membrane. American Journal of Pathology 76, 285-312.

HUET, M. (1975). Factors affecting the molecular structure and the agglutinating ability of concanavalin A and other lectins. European Journal of Biochemistry 59, 627-632.

Huet, CH. \& Garrido, J. (1972). Ultrastructural visualization of cell-coat components by means of wheat germ agglutinin. Experimental Cell Research 75, 523-527.

IsAaC, S., Ryder, N. S. \& Peberdy, J. F. (1978). Distribution and activation of chitin synthase in protoplast fractions released during the lytic digestion of Aspergillus nidulans hyphae. Journal of General Microbiology 105, 45-50.

JAN, Y. N. (1974). Properties and cellular localization of chitin synthetase in Phycomyces blakesleeanus. Journal of Biological Chemistry 249, 1973-1979.

KATZ, D. \& Rosenberger, R. F. (1971). Hyphal wall synthesis in Aspergillus nidulans: effect of protein synthesis inhibition and osmotic shock on chitin insertion and morphogenesis. Journal of Bacteriology 108, 184-190. 
Laere, A. J. Van \& Carlier, A. R. (1978). Synthesis and proteolytic activation of chitin synthase in Phycomyces blakesleeanus Burgeff. Archives of Microbiology 116, 181-184.

Lopez-Romero, L. \& Ruiz-Herrera, J. (1976). Synthesis of chitin by particulate preparations from Aspergillus flavus. Antonie van Leeuwenhoek 42, 261-276.

McMurrough, I., Flores-Carreon, A. \& BartNICKI-GARCIA, S. (1971) Pathway of chitin synthesis and cellular localization of chitin synthetase in Mucor rouxii. Journal of Biological Chemistry 246, 3999-4007.

Nicolson, G. L. (1974). Interactions of lectins with animal cell surfaces. International Review of Cytology 39, 89-190.

Peberdy, J. F. \& Moore, P. M. (1975). Chitin synthase in Mortierella vinacea: properties, cellular location and synthesis in growing cultures. Journal of General Microbiology 90, 228-236.

Ruiz-Herrera, J. \& Bartnicki-Garcia, S. (1974). Synthesis of cell wall microfibrils in vitro by a 'soluble' chitin synthetase from Mucor rouxii. Science 186, 357--359.

Ruiz-Herrera, J. \& Bartnicki-Garcia, S. (1976). Proteolytic activation and inactivation of chitin synthetase from Mucor rouxii. Journal of General Microbiology 97, 241-249.

Ruiz-Herrera, J., Sing, V. O., Van der Woude, W. J. \& BARTNICKI-GARCIA, S. (1975). Microfibril assembly by granules of chitin synthetase. Proceedings of the National Academy of Sciences of the United States of America 72, 2706-2710.

Ryder, N. S. \& Peberdy, J. F. (1977). Chitin synthase in Aspergillus nidulans: properties and proteolytic activation. Journal of General Microbiology 99, 69-76.
Scarborough, G. A. (1975). Isolation and characterization of Neurospora crassa plasma membranes. Journal of Biological Chemistry 250, $1106-1111$.

Sietsma, J. H. \& Wessels, J. G. H. (1977). Chemical analysis of the hyphal wall of Schizophyllum commune. Biochimica et biophysica acta 496, 225-239.

Skujins, J. J., Potgieter, H. J. \& Alexander, M. (1965). Dissolution of fungal cell walls by a streptomycete chitinase and $\beta$-(1-3)-glucanase. Archives of Biochemistry and Biophysics 111, 358-364.

Smith, S. B. \& Revel, J. (1972). Mapping of concanavalin A binding sites on the surface of several cell types. Developmental Biology 27, 434-441.

VAlK, P. VAN DER \& Wessels, J. G. H. (1976). Ultrastructure and localization of wall polymers during regeneration and reversion of protoplasts of Schizophyllum commune. Protoplasma 90 , $65-87$.

VALK, P. VAN DER \& Wessels, J. G. H. (1977). Light and electron microscopic autoradiography of cell-wall regeneration by Schizophyllum commune protoplasts. Acta botanica neerlandica 26, 43-52.

VRIES, O. M. H. DE \& Wessels, J. G. H. (1975). Chemical analysis of cell wall regeneration and reversion of protoplasts from Schizophyllum commune. Archives of Microbiology 102, 209-218.

Wessels, J. G. H. (1965). Morphogenesis and biochemical processes in Schizophyllum commune Fr. Wentia 13, 1-113.

Williamson, F. A., Fowke, L. C., Constabel, F. C. \& GAMBorg, O. L. (1976). Labelling of concanavalin A sites on the plasma membrane of soybean protoplasts. Protoplasma 89, 305-316. 